\title{
The influence of diol addition on water crystallization kinetics in mesopores
}

\author{
Dalia Bednarska' (D) Marcin Koniorczyk ${ }^{1}$
}

Received: 30 November 2018/Accepted: 27 April 2019/Published online: 15 May 2019

(C) The Author(s) 2019

\begin{abstract}
Solidification of liquid occupying material's pores is one of the main reasons of its skeleton deterioration. So far, it has been usually assumed that confined water undergoes phase transitions more rapidly than temperature changes, which indicates that the kinetic effects are negligible. However, this assumption is often infringed. The main object of this paper is to analyse the crystallization of commonly applied antifreeze, i.e. ethylene as well as propylene glycol, in water solutions contained in voids of mesoporous silica gel with average pore size equal to $11 \mathrm{~nm}$. In case of both solutions, two concentrations are analysed, $5 \%$ and $10 \%$. Additionally, the analysis is conducted also for deionized water. The experimental research has been conducted by means of differential scanning calorimetry with multiple cooling rate program applied. The activation energy is estimated according to the differential Friedman method. In order to pick the most appropriate kinetic model to analysed phenomenon, two approaches are applied: the one introduced by Málek as well as the one described by Perez-Maqueda et al., the so-called model-fitting method. The former indicates the Šesták-Berggren model, whereas the latter points to $n$th reaction order model. Both equations demonstrate high accordance with the experimental data. The Šesták-Berggren equation is an empirical formula, which does not provide any explanation about antifreeze solidification. However, the $n$th reaction order model belongs to the group of geometrical extension/contraction models.
\end{abstract}

Keywords Kinetics · Water freezing · Ethylene glycol solution · Propylene glycol solution · Mesopores · Nucleation $\cdot$ Silica gel

\section{Introduction}

Most of materials employed in industry are porous. The material void spaces can be filled with water vapour or liquid water with miscellaneous contaminations dissolved. Water expands its volume by about $9 \%$ during freezing $[1,2]$. Hence, damage of material skeleton can occur especially in case of temperature decrease. The freezing temperature of water contained in pores is decreased in comparison with bulk water, which is described by GibbsThomson formula [3-5]:

Dalia Bednarska

dalia.bednarska@p.lodz.pl

1 Department of Building Physics and Building Materials, Lodz University of Technology, Politechniki 6, 90-924 Łódź, Poland
$\Delta T_{\mathrm{m}}=\frac{2 T_{0} \gamma_{\mathrm{cl}}}{\rho_{1} \Delta H_{\mathrm{f}}} \frac{\cos \theta}{r_{\mathrm{p}}-\delta}$

where $T_{0}$ is the temperature of bulk liquid melting, $\gamma_{\mathrm{cl}}$ is solid/liquid surface tension, $\rho_{1}$ is the liquid density, $\Delta H_{\mathrm{f}}$ is the heat of fusion, $r_{\mathrm{p}}$ is the pore radius, $\delta$ is the thickness of the unfrozen liquid layer and $\theta$ is the contact angle. It is also observed that during freezing there always remains a thin liquid layer between ice and pore wall $[5,6]$.

The in-pore crystallization is concerned as the major cause of material's microstructure damage, which is why it is a frequent subject of scientific research [7-11]. In vast majority of papers authors assume that temperature changes so slow that considered system remains in thermodynamic equilibrium [12, 13]. However, this condition might be sometimes violated, e.g. during fire in cold climate. In such a situation, when the turbulent heat flow occurs, the kinetic effects cannot be neglected. Phase transitions of inpore liquid in case of non-equilibrium conditions were 
previously investigated by Setzer [14, 15]. Bronfenbrener et al. introduced a simple model describing mass and energy transport during water phase transition concerning the kinetic effects $[16,17]$. Their approach is based on the characteristic time parameter, which remains constant and is not influenced by material microstructure.

So far, a lot of research, which concerns homogenous nucleation of bulk water, has been conducted [18, 19]. However, such crystallization may occur only in sterile, laboratory conditions in case of deionized liquid. In previous papers, we analysed the kinetics of heterogenous crystallization of water confined in mesopores of silica gel [20-22]. It has been confirmed that it is a thermally activated process. It has been also proved that the empirical Šesták-Berggren model reflects the experimental data in the best way. The aim of presented research is to investigate the phase transition of in-pore liquid during rapid temperature changes. This time in addition to deionized water, we intend to analyse the phase transition kinetics of ethylene and propylene glycol in water solution, which are commonly applied as antifreeze. The solidification kinetics of such substances has not been described yet. The mesoporous silica gel with dominant pore diameter of $11 \mathrm{~nm}$ is used as a saturated material. The main purpose of this paper is to investigate the mechanism, according to which a solidification of coolant solution happens. To achieve this goal, we determine the parameters of reaction rate function, i.e. the activation energy, the pre-exponential factor and the kinetic model, for analysed antifreeze solutions. As possible kinetic equations describing the antifreeze solutions, we analysed the following models: nucleation and nuclei growth model, geometrical contraction model, diffusion model and order-based model. To estimate the kinetic mechanism, we applied the algorithm proposed by Málek [23], which is recommended by the International Confederation for Thermal Analysis and Calorimetry (ICTAC) [24]. In this case, the activation energy is estimated on the basis of Friedman method [25]. As the alternative procedure for kinetic model determination, the linear modelfitting method described by Perez-Maqueda et al. is applied $[26,27]$. In this paper, we affirm that both of those approaches are suitable ways of finding the kinetic equation describing diol solution crystallization in silica gel mesopores. The experimental research is conducted by means of differential scanning calorimetry (DSC), which is a multi-purpose thermoanalytical tool applied in nearly every branch of science [28, 29]. The non-isothermal program is with the following cooling rates employed: $2.5^{\circ} \mathrm{C} \mathrm{min}{ }^{-1}, \quad 5.0^{\circ} \mathrm{C} \mathrm{min}^{-1}, \quad 7.5^{\circ} \mathrm{C} \mathrm{min}^{-1}$ and $10.0^{\circ} \mathrm{C} \mathrm{min}^{-1}$. Additionally, the slowest rate $0.5^{\circ} \mathrm{C}$ $\mathrm{min}^{-1}$ is introduced in order to conduct calibration procedure. Moreover, the nitrogen absorption/desorption analysis is conducted in order to examine the possible influence of cyclic water freezing from the solution on the silica gel microstructure.

\section{Experimental and theoretical methods}

The energy effects connected to phase transition of analysed liquids are recorded by means of Perkin-Elmer DSC 4000 calorimeter equipped with a refrigerated cooler. The gaseous nitrogen of $99.999 \%$ quality is provided by Linde Gas. In order to correct the temperature, the heat response of water droplet is measured at various heating rates [30] (which are applied in further analysis). The peak onset temperature of heating, which is interpreted as the initial temperature of transition process, is determined for each temperature program, and subsequently, the correction is obtained by extrapolation $T_{\text {onset }}$ to cooling rate $\beta \rightarrow 0$, which is presented in Fig. 1.

The temperature recorded by DSC within the proper analysis is revised according to equation:

$T+T_{\text {onset }, \beta} \rightarrow T_{\text {true }}, \quad \beta \rightarrow 0$.

\section{Material properties}

Silica gel is chosen as the subject matter of the experimental investigation. Silicon dioxide is a synthetically obtained substance, which forms porous structure and can absorb liquids up to $40 \%$ of its own mass. This granular, vitreous material is produced from sodium silicate. The connected hydrophilic pores comprise an extensive surface area, which attracts water by adsorption and capillary condensation. Hence, the main application of silica gels is desiccation and local humidity maintenance. Moreover, the

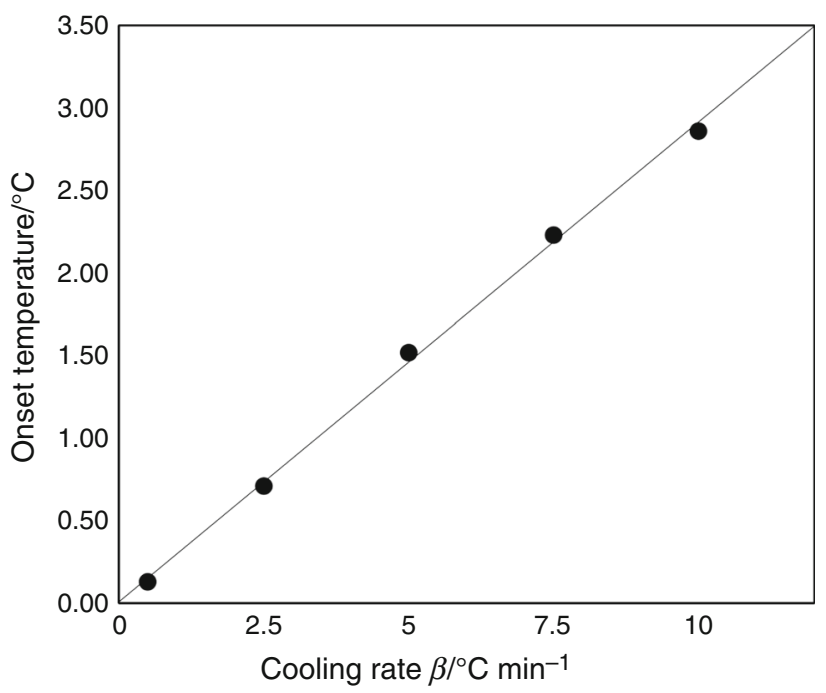

Fig. 1 Extrapolated onset temperature $T_{\text {onset }}$ as a function of the heating rate $\beta$ 
material is commonly used as stationary phase in chromatography and active phase supports in heterogeneous catalysis. The silica gel applied in the experimental research is supplied by Sigma-Aldrich Co. The producer declares structure properties of the material as follows:

SG1 (Sigma-Aldrich Co., No. 236845)

- Dominant pore diameter: $15 \mathrm{~nm}$,

- Particle size: $250-500 \mu \mathrm{m}$,

- Pore volume: $1.15 \mathrm{~cm}^{3} \mathrm{~g}^{-1}$,

- Surface area: $300 \mathrm{~m}^{2} \mathrm{~g}^{-1}$.

In order to examine the influence of cyclic freezing on silica gel microstructure as well as to verify the structural properties of material, the nitrogen adsorption-desorption test is conducted. The study is realized by means of Micromeritics ASAP 2020 equipment. In addition to adsorption and desorption isotherms, the specific surface area and pore size distribution are determined. The former parameter is estimated according to BET model. The assumption that nitrogen molecules cover area of $0.162 \mathrm{~nm}^{2}$ is made. In case of latter one, the Barrett-Joyner-Halenda (BJH) model is used. The test is conducted for two kinds of samples: the reference one as well as the one saturated with $10 \%$ ethylene glycol solution and subjected to ten freezing cycles. Entirely dry samples are investigated. After inserting samples into measurement crucibles, one has to degas them. Subsequently, the sorption process occurs at $-195{ }^{\circ} \mathrm{C}$. The obtained results are presented in Table 1 and Fig. 2. According to device producer declaration, the error of specific surface area measurement is estimated at $2 \%$. Hence, slight difference between the parameters determined for both kinds of samples is within the error and one has to assume that cyclic freezing does not affect silica gel microstructure. The obtained textural parameters for investigated samples are in a good accordance with those declared by the silica gel producer.

The shapes of the obtained isotherms indicate that they represent the IV type according to IUPAC classification. The pore size distributions are unimodal, which proves that investigated material is characterized by pores of one dominant size. In the recorded isotherms, one can notice the capillary condensation step, which corresponds to nitrogen capillary condensation and an evaporation step,

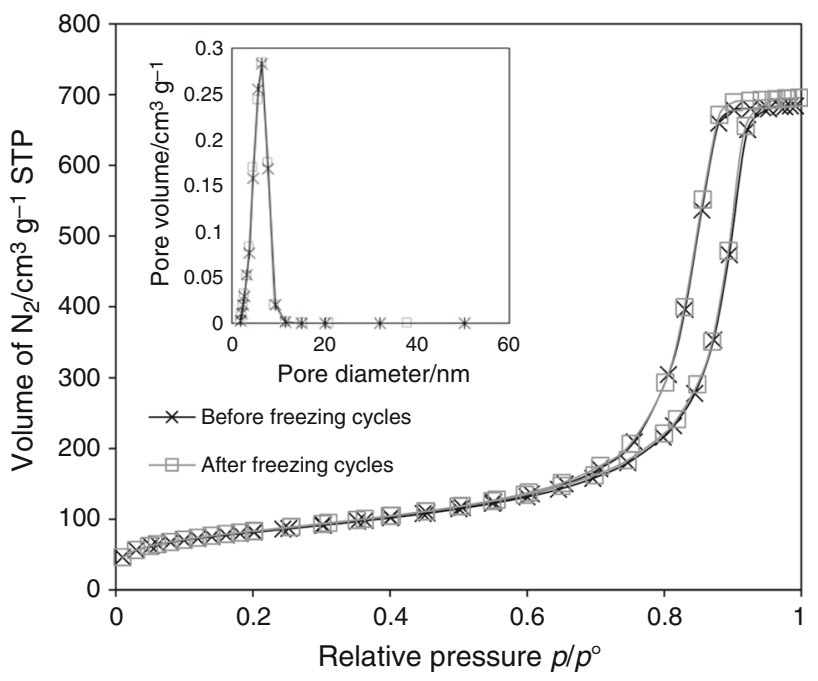

Fig. 2 Nitrogen adsorption-desorption isotherms for virgin sample and sample containing $10 \%$ ethylene glycol solution after 10 freezing cycles

which implies nitrogen evaporation from pores. Those observations are indicative of regular material microstructure composed of pores of uniform diameters. The results obtained for both kinds of samples are equal, which indicates that the influence of diol solution freezing on the silica gel microstructure is negligible. Hence, one can assume that the results of kinetic analysis are not affected by the alteration of material microstructure.

Solutions of two types of diols, ethylene glycol and propylene glycol, are applied as liquids, which fill in the silica gel mesopores. Propylene glycol, as distinct from ethylene glycol, is a nontoxic substance. Ethylene glycol, also called ethane-1,2-diol, is a clear, odourless, viscous liquid. It is the simplest member of glycols. Propylene glycol, also called propane-1,2-diol, resembles ethylene glycol in its physical properties. Additionally, it contains a chiral carbon atom and exists thus in two enantiomers. They are commonly applied as antifreeze formulations or recently as a base liquid in nanofluids, which attract scientists' attention due to superior thermophysical properties [31-33]. Aqueous solutions of concentrations 5\% and $10 \%$ for each glycol are prepared. The heat of fusion of distilled water is given by the equation $[34,35]$ :

Table 1 Textural parameters of silica gel determined by the $\mathrm{N}_{2}$ adsorption-desorption

\begin{tabular}{|c|c|c|c|c|}
\hline Sample & Treatment & $\begin{array}{l}\text { Specific surface area } \\
\mathrm{SSA} / \mathrm{m}^{2} \mathrm{~g}^{-1}\end{array}$ & $\begin{array}{l}\text { Total pore volume/ } \\
\mathrm{cm}^{3} \mathrm{~g}^{-1}\end{array}$ & $\begin{array}{l}\text { Average pore } \\
\text { diameter/nm }\end{array}$ \\
\hline SG1 & Virgin sample & 287 & 1.08 & 11.2 \\
\hline SG1 & $\begin{array}{l}\text { Sample saturated with } 10 \% \text { ethylene glycol solution and } \\
\text { subjected to } 10 \text { freezing cycles }\end{array}$ & 292 & 1.09 & 11.3 \\
\hline
\end{tabular}


$\Delta H_{\mathrm{f}}=334.1+2.119\left(T-T_{0}\right)-0.00783\left(T-T_{0}\right)^{2}$.

The thermodynamic properties of applied solutions are presented in Table 2.

\section{Experimental procedure}

Applying linear temperature program does not enable user to differentiate the dependence of temperature and reacted fraction from the reaction rate [24, 26]. Hence, the experimental procedure is designed as multitemperature program. The applied program consists of four cooling cycles with the temperature rate equalling $2.5^{\circ} \mathrm{C} \mathrm{min}{ }^{-1}$, $5.0{ }^{\circ} \mathrm{C} \min ^{-1}, 7.5{ }^{\circ} \mathrm{C} \min ^{-1}$ and $10.0{ }^{\circ} \mathrm{C} \min ^{-1}$. An auxiliary freezing cycle before each of such main temperature cycle is designed. It consists of cooling sample down to $-40{ }^{\circ} \mathrm{C}$ and heating it up to $-0.1{ }^{\circ} \mathrm{C}$ with a rate $1.0{ }^{\circ} \mathrm{C} \min ^{-1}$. The reason of introducing such preliminary cycle is to ensure the presence of ice nuclei in the confined water and moreover to enable to differentiate between the signal corresponding to transitions of excess water and the one related to confined water. The kinetic analysis is conducted on the basis of DSC cooling scans. Then, two equal portions of dry material are put into two crucibles. Additionally, one of the prepared samples is oversaturated with distilled water or diol solution, respectively. The crucible with dried material is placed in the reference side of the DSC furnace whereas the second one in the sample side. Some excessive amount of water or glycol solution is added during saturation. As mentioned before, the signal corresponding to this additional liquid is eliminated by auxiliary cooling cycles, which is why only signal connected to pore-confined liquid freezing is considered in further kinetic analysis. The experimental research is repeated for all of prepared glycol solutions as well as for deionized water. The kinetic analysis is conducted on data representing mean values of three DSC programs performed for particular samples. The temperatures recorded during cooling cycles are determined in accordance with the onset temperature of excess water melting. It is reproducible within $\pm 0.10{ }^{\circ} \mathrm{C}$ for all scans.

\section{Theoretical background}

The main purpose of kinetic analysis is to determine the reaction rate function. One of its parameter is the so-called conversion extent $\alpha$, which corresponds to the transition progress, so $\alpha \in[0,1]$. Every phase transition is connected to energetic effect, which is why $\alpha$ can be determined according to the equation [36, 37]:

$\alpha(t)=\frac{\Delta Q_{\mathrm{t}}}{\Delta Q_{\text {Total }}}=\int_{t_{0}}^{t}\left(\frac{\mathrm{d} Q}{\mathrm{~d} t}\right) \mathrm{d} t / \int_{t_{0}}^{t_{\infty}}\left(\frac{\mathrm{d} Q}{\mathrm{~d} t}\right) \mathrm{d} t$

where $Q$ is the heat exuded during a phase transition, $t_{0}$ is the initial time, $t$ is the random time and $t_{\infty}$ is the total time of the reaction. The reaction rate function depends on three parameters-temperature $T$, pressure $p$ and the extent of conversion $\alpha$. However, if gaseous reactants do not participate in the reaction, the influence of pressure is negligible [24]. Therefore, the process rate $\mathrm{d} \alpha / \mathrm{d} t$ is the product of two compounds:

$\frac{\mathrm{d} \alpha}{\mathrm{d} t}=k(T) f(\alpha)$

where $k(T)$ is the rate constant and $f(\alpha)$ is the kinetic reaction model. It has to be emphasized that Eq. (5) is reasonable only in case of single reaction process. The dependence between the rate constant and temperature is determined on the basis of Arrhenius equation:

$k(T)=A \exp \left(\frac{-E_{\alpha}}{R T}\right)$

where $A$ is the pre-exponential factor $\left[\mathrm{min}^{-1}\right]$ corresponding to frequency and orientation of molecules collisions and $E_{\alpha}$ is the activation energy $\left[\mathrm{kJ} \mathrm{mol}^{-1}\right]$, which is treated as the energetic barrier and has to be overcome so that the transition can occur. $R$ is the universal gas constant, which equals $8.314 \mathrm{~J} \mathrm{~mol}^{-1} \mathrm{~K}^{-1}$.
Table 2 Thermodynamic properties of employed solutions [38]
Enthalpy of fusion, $\Delta H_{\mathrm{f}} / \mathrm{J} \mathrm{g}^{-1}$

\begin{tabular}{ll}
\hline $\begin{array}{l}\text { Ethylene glycol } \\
\text { Pure substance }\end{array}$ & 160.46 \\
$5 \%$ solution & $0.95 \cdot\left[334.1+2.119\left(T-T_{0}\right)-0.00783\left(T-T_{0}\right)^{2}\right]+0.05 \cdot 160.46$ \\
$10 \%$ solution & $0.90 \cdot\left[334.1+2.119\left(T-T_{0}\right)-0.00783\left(T-T_{0}\right)^{2}\right]+0.10 \cdot 160.46$ \\
Propylene glycol & 107.50 \\
Pure substance & $0.95 \cdot\left[334.1+2.119\left(T-T_{0}\right)-0.00783\left(T-T_{0}\right)^{2}\right]+0.05 \cdot 107.50$ \\
$5 \%$ solution & $0.90 \cdot\left[334.1+2.119\left(T-T_{0}\right)-0.00783\left(T-T_{0}\right)^{2}\right]+0.10 \cdot 107.50$ \\
$10 \%$ solution &
\end{tabular}


By inserting Eq. (6) into Eq. (5), we obtain:

$\frac{\mathrm{d} \alpha}{\mathrm{d} t}=A \exp \left(\frac{-E_{\alpha}}{R T}\right) f(\alpha)$.

The DSC program consists of scanning steps with constant cooling rates $\beta$. Hence, the following expression is valid:

$\beta=\frac{\mathrm{d} T}{\mathrm{~d} t}=$ const.

One has to emphasize that $\beta$ is negative. This fact has to be taken into consideration before one chooses a method, according to which the activation energy is determined [39]. By combining Eq. (7) and Eq. (8), the final equation for the constant heating/cooling rate is obtained:

$\frac{\mathrm{d} \alpha}{\mathrm{d} t}=\beta \frac{\mathrm{d} \alpha}{\mathrm{d} T}=A \exp \left(\frac{-E_{\alpha}}{R T}\right) f(\alpha)$.

\section{Activation energy}

The isoconversional methods are currently commonly applied to kinetics calculations due to their high reliability [40-42]. They are based on the assumption that the process rate at constant extent of conversion is solely a function of temperature [37, 39]. As a result, the activation energy can be estimated without establishing any reaction model, which is why these methods are often called "model-free" ones. On the other hand, they assume that the extent of conversion-temperature relation obeys $f(\alpha)$ model. There are two types of isoconversional methods: differential and integral. Due to our previous findings [22], the differential method introduced by Friedman [25] is applied. It is based on the differential form of reaction rate function. After applying the isoconversional principle to Eq. (9), we obtain:

$\ln \left(\frac{\mathrm{d} \alpha}{\mathrm{d} t}\right)_{\alpha, \beta}=\ln [A f(\alpha)]-\frac{E_{\alpha}}{R T_{\alpha, \beta}}$.

Activation energy $E_{\alpha}$ corresponds to the slopes of relation between $\ln \left(\frac{\mathrm{d} \alpha}{\mathrm{d} t}\right)_{\alpha, \beta}$ and the reciprocal temperature $1 / T_{\alpha, \beta}$, which are analysed for each extent of conversion value, $\alpha$, and index $\beta$ denotes various thermal cycles.

\section{Kinetic model determination}

The appropriate kinetic model is determined by means of the algorithm introduced by Málek [23]. According to this method, one has to analyse two auxiliary functions dependent on extent of conversion, $y(\alpha)$ and $z(\alpha)$. The functions are defined as follows: $y(\alpha)=\left(\frac{\mathrm{d} \alpha}{\mathrm{d} t}\right)_{\alpha} \exp \left(\frac{E_{\alpha}}{R T_{\alpha}}\right)=A f(\alpha)$

$z(\alpha)=\left(\frac{\mathrm{d} \alpha}{\mathrm{d} t}\right)_{\alpha} T_{\alpha}^{2}\left[\frac{\pi(x)}{\beta T}\right]_{\alpha}$

where $x=\frac{E_{\alpha}}{R T}$. ICTAT KC recommends [24] to neglect the expression in brackets in Eq. (12) because of an infinitesimal influence on $z(\alpha)$ function. The method is based on the analysis of shapes and maximum values of these auxiliary functions and selection of the most suitable kinetic model by comparing those features obtained for experimental data with most popular models, see Table 3. Functions $y(\alpha)$ and $z(\alpha)$ are investigated as normalized ones, i.e. given in the interval $[0,1]$. Parameters $\alpha_{\mathrm{p}}, \alpha_{\mathrm{M}}$ and $\alpha_{\mathrm{p}}^{\infty}$ correspond to the maximum values of $\mathrm{d} \alpha / \mathrm{d} t(\alpha), y(\alpha)$ and $z(\alpha)$ function, respectively.

The second algorithm applied in order to determine the kinetic model of studied phenomena is the one implemented by Pérez-Maqueda et al. [26, 27]. The researchers found that Šesták-Berggren equation introduced in a modified form can correspond to vast majority of kinetic models, which are commonly applied nowadays. The Šesták-Berggren equation is an entirely empirical formula, which does not provide any physical explanation of the processes behind crystallization. After introducing constant $c$, the equation reflects many of the most popular kinetic model functions, which are commonly applied nowadays [26, 27]:

$f(\alpha)=c(1-\alpha)^{n} \alpha^{m}$.

\section{Results and discussion}

The differential scanning calorimetry is an universal method, which enable users to investigate processes connected to heat effects. The extent of conversion is proportional to the net heat recorded by the calorimeter during

Table 3 The basic kinetic models [23, 24]

\begin{tabular}{lll}
\hline Model & Symbol & $f(\alpha)$ \\
\hline Johnson-Mehl-Avrami & $\operatorname{JMA}(p)$ & $p(1-\alpha)[-\ln (1-\alpha)]^{1-1 / \mathrm{p}}$ \\
Reaction order & $\mathrm{RO}(n)$ & $(1-\alpha)^{\mathrm{n}}$ \\
2D reaction & $\mathrm{R} 2$ & $2(1-\alpha)^{1 / 2}$ \\
3D reaction & $\mathrm{R} 3$ & $3(1-\alpha)^{2 / 3}$ \\
2D diffusion & $\mathrm{D} 2$ & $1 /[-\ln (1-\alpha)]$ \\
Jander equation & $\mathrm{D} 3$ & $1.5(1-\alpha)^{2 / 3} /\left[1-(1-\alpha)^{2 / 3}\right]$ \\
Ginstling-Brounshtein & $\mathrm{D} 4$ & $1.5\left[(1-\alpha)^{-1 / 3}-1\right]$ \\
Šesták-Berggren & $\mathrm{SB}(m, n)$ & $\alpha^{\mathrm{m}}(1-\alpha)^{\mathrm{n}}$ \\
\hline
\end{tabular}


(a)

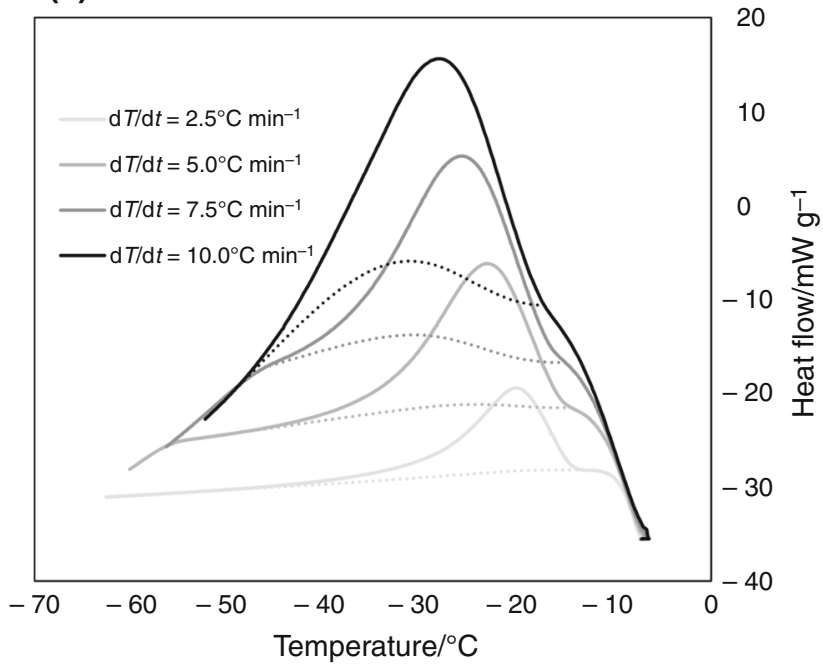

(c)

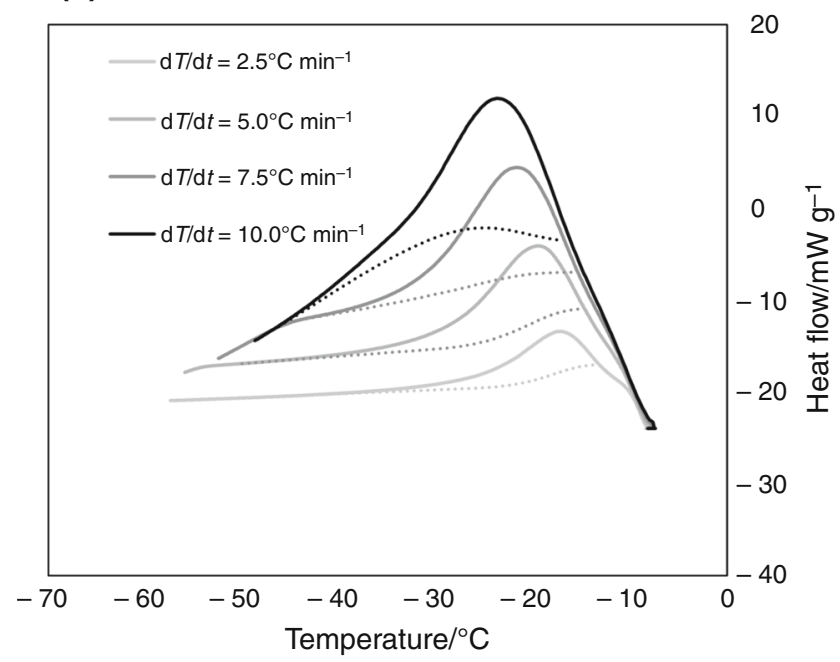

(b)

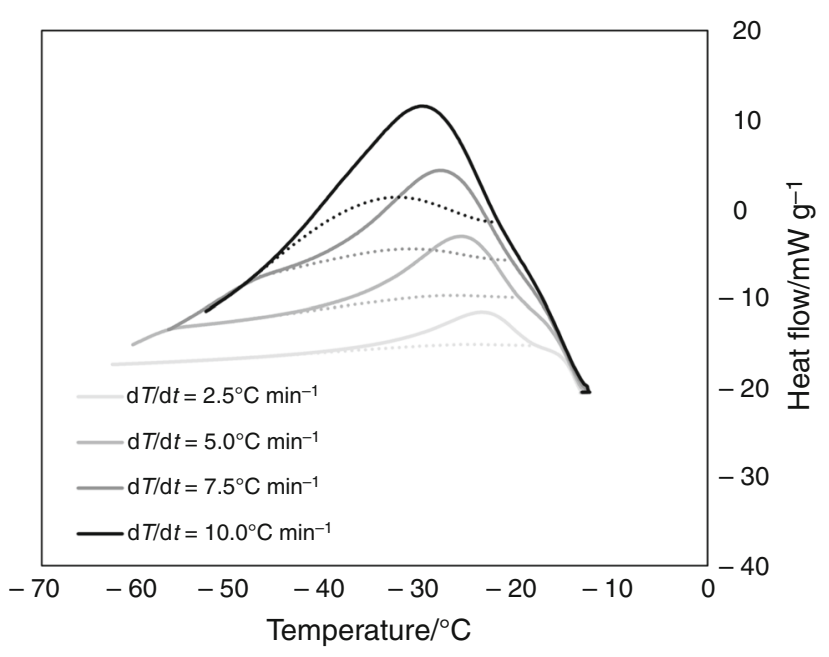

(d)

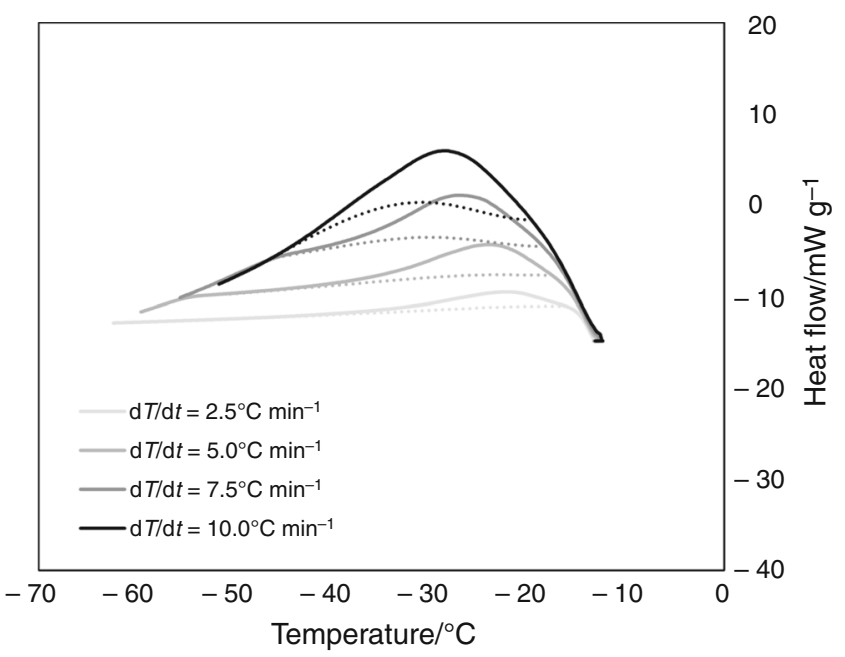

(e)

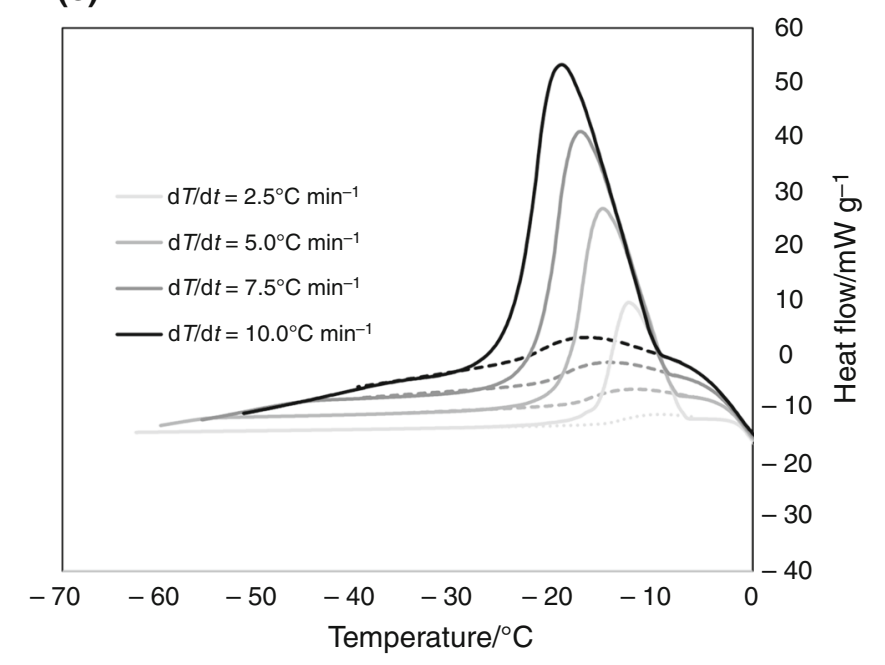

Fig. 3 DSC curves versus temperature under various cooling rates obtained for 5\% ethylene glycol solution (a), 10\% ethylene glycol solution (b), 5\% propylene glycol solution (c), $10 \%$ propylene glycol solution (d) and water (e) 


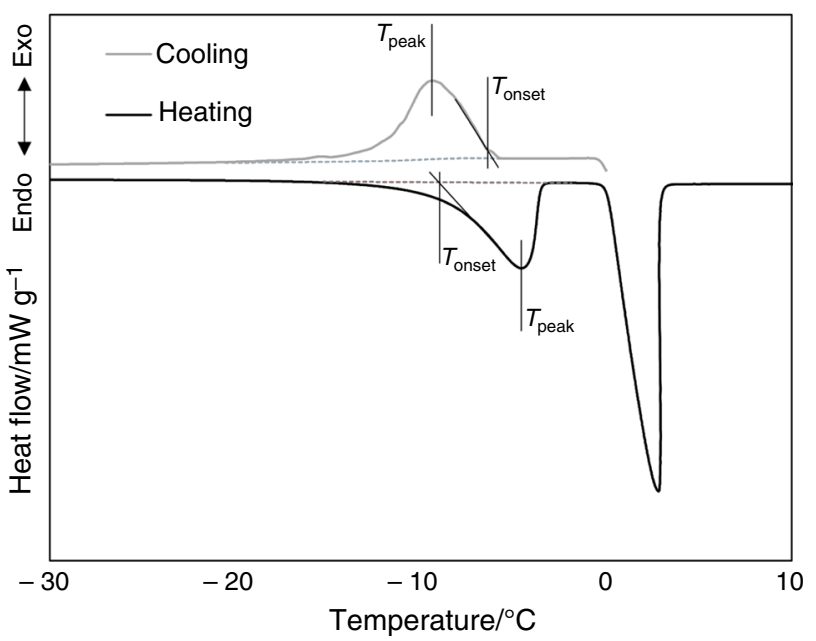

Fig. 4 Freezing-melting hysteresis recorded for deionized water by DSC at the slowest rate $\beta=0.5^{\circ} \mathrm{C} \mathrm{min}^{-1}$

the transition. The net heat is proportional to the peak area, which is established by applying a baseline. This is an auxiliary line corresponding to steady-state conditions. It would be registered by calorimeter if all specific heat fluctuations occurred, but no heat of transition was released. In this paper, the method described by Michaelsen and Dahms [43] is applied in order to determine a proper baseline. The approach consists in the assumption that a baseline is a combination of DSC curves recorded before and after transition. Additionally, it is proportional to the extent of conversion:

$\left.\frac{\mathrm{d} Q}{\mathrm{~d} t}\right|_{\text {base }}=\left.\frac{\mathrm{d} Q}{\mathrm{~d} t}\right|_{-}(1-\alpha)+\left.\frac{\mathrm{d} Q}{\mathrm{~d} t}\right|_{+} \alpha$

Figure 3 presents DSC curves as well as the baselines determined for each cooling rate $\beta$ and each material under investigation. The peaks and onset temperatures are proportional to the cooling rate. It implies that the pressure in liquid might be negligible or it has constant effect on each DSC curve independently of cooling rate [36, 37].

The onset temperatures determined on the basis of the experimental data (whose definition is presented in Fig. 4) compared to the literature values for each investigated material are presented in Table 4. The onset temperature corresponds to melting of bulk ice.

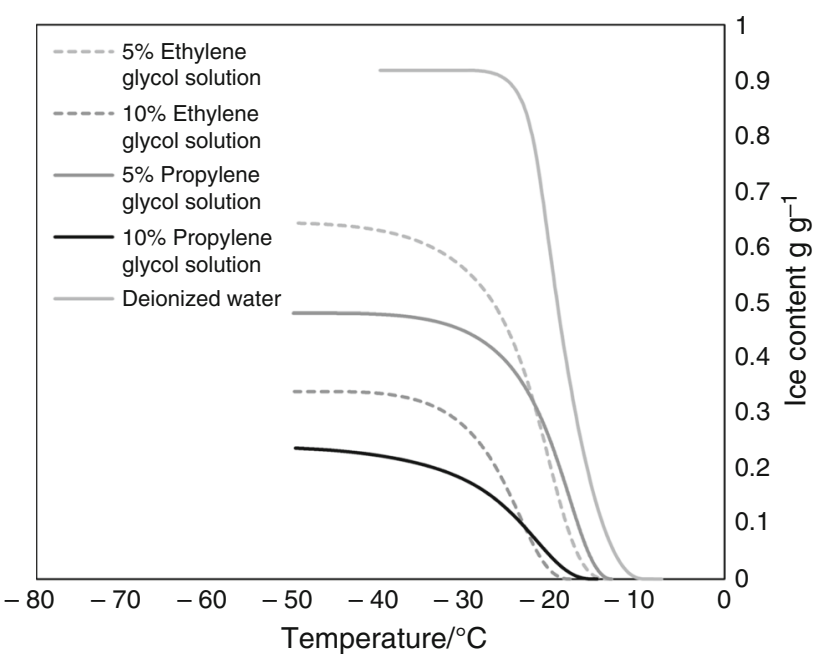

Fig. 5 Ice content versus temperature under the slowest cooling rate for 5\% ethylene glycol solution (a), 10\% ethylene glycol solution (b), $5 \%$ propylene glycol solution (c), $10 \%$ propylene glycol solution (d) and water (e)

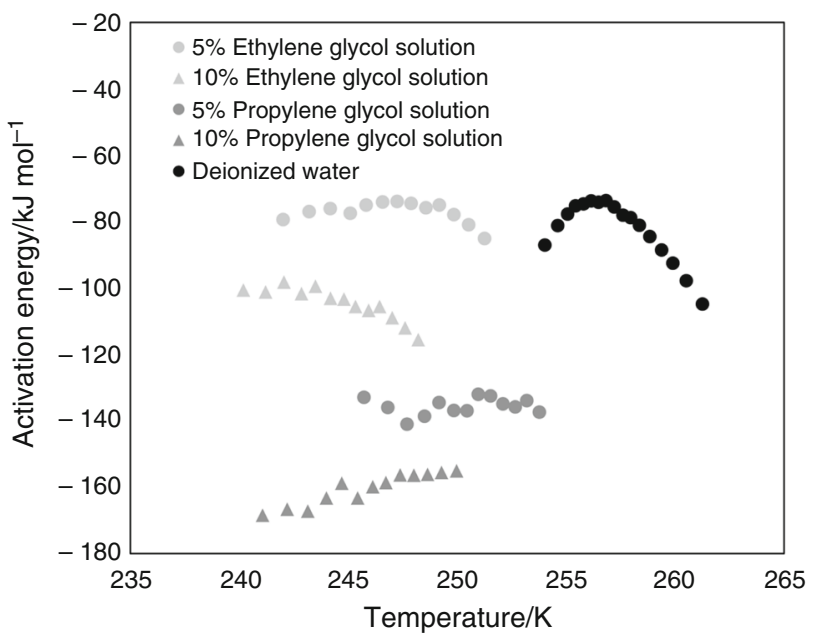

Fig. 6 Activation energy vs temperature obtained by means of Friedman method for 5\% ethylene glycol solution, $10 \%$ ethylene glycol solution, $5 \%$ propylene glycol solution, $10 \%$ propylene glycol solution and deionized water

The inconsistency between both values springs from the fact that the literature value has been measured by means of entirely different method, which is introduced by
Table 4 The comparison between onset temperatures and freezing points for analysed solutions [44, 45]

\begin{tabular}{llc}
\hline & $\begin{array}{l}T_{\text {onset }} /{ }^{\circ} \mathrm{C} \\
\text { experimental value }\end{array}$ & $\begin{array}{l}T /{ }^{\circ} \mathrm{C} \\
\text { literature value }\end{array}$ \\
\hline $5 \%$ Ethylene glycol solution & -3.67 & -1.80 \\
$10 \%$ Ethylene glycol solution & -6.84 & -3.60 \\
$5 \%$ Propylene glycol solution & -3.10 & -1.50 \\
$10 \%$ Propylene glycol solution & -4.27 & -3.00
\end{tabular}


Table 5 The average values of activation energy

\begin{tabular}{ll}
\hline & Activation energy $E_{a} / \mathrm{kJ} \mathrm{mol}^{-1}$ \\
\hline Deionized water & -79.097 \\
$5 \%$ Ethylene glycol solution & -77.085 \\
10\% Ethylene glycol solution & -104.76 \\
5\% Propylene glycol solution & -135.655 \\
$10 \%$ Propylene glycol solution & -164.645
\end{tabular}

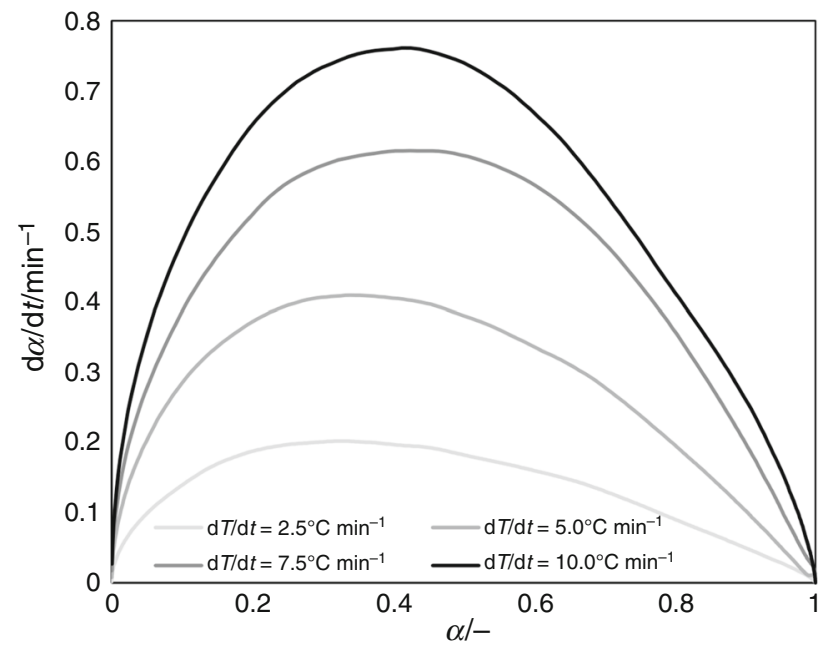

Fig. $7 \mathrm{~d} \alpha / \mathrm{d} t$ function in extent of conversion $\alpha$ domain for particular cooling rates determined for material saturated with $10 \%$ propylene glycol solution

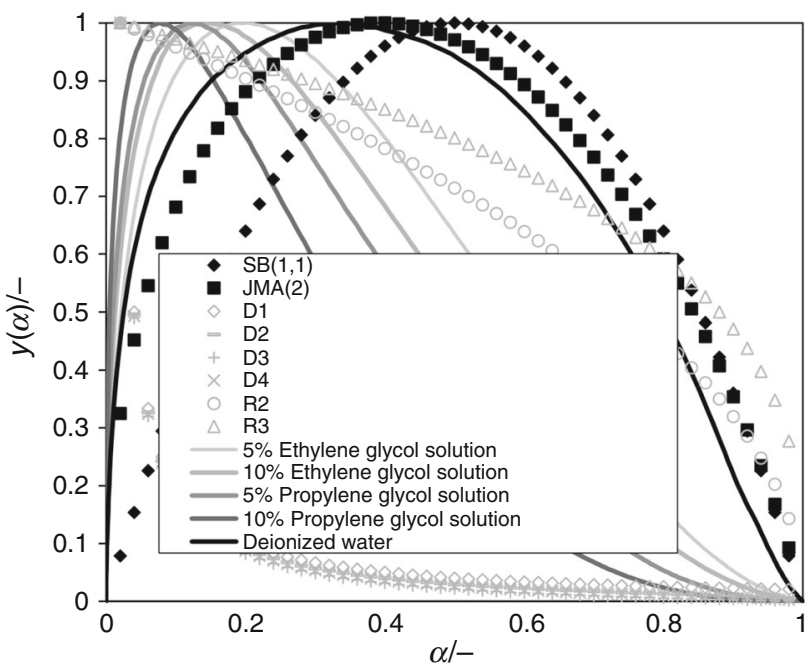

Fig. 8 Shapes of masterplot $y(\alpha)$ for basic kinetic models and experimental data determined for temperature rate $5.0{ }^{\circ} \mathrm{C} \mathrm{min}^{-1}$ for particular samples
Fig. 9 Comparison of results obtained using the Málek method for SB model with experimental data for 5\% ethylene glycol solution (a), $10 \%$ ethylene glycol solution (b), 5\% propylene glycol solution (c), $10 \%$ propylene glycol solution (d) and water (e)

American Society for Testing and Materials [46]. In this case, the temperature of analysed coolant has been monitored by means of thermocouples and the output data have been plotted as the function of time. Moreover, as the freezing point, the authors considered the maximum temperature recorded during temperature increase related to the solidification of overcooled liquid-see Fig. 4.

For DSC test, the characteristic phase change temperature is determined as the onset temperature for the signal associated with the arbitrary conversion during the heating program. In case of heating, two peaks are recorded (Fig. 4), the former, which is related to the melting of inpore ice, and the latter connected to the bulk water melting, which occurs around $0{ }^{\circ} \mathrm{C}$. The amount of ice developed during investigated transitions is estimated by means of the following formula:

$\frac{\mathrm{d} m}{\mathrm{~d} t}=\frac{1}{\Delta H_{\mathrm{f}}} \frac{\mathrm{d} Q}{\mathrm{~d} t}$

where $\Delta H_{\mathrm{f}}$ is the heat of transition and $\frac{\mathrm{d} Q}{\mathrm{~d} t}$ is the net heat detected by calorimeter. The relation between conversion extent and time for each cooling is obtained by integrating Eq. (9). In Fig. 5, there is an increase in the amount of arisen ice in temperature domain for particular materials under investigation.

The ice content is determined in grams of ice per gram of dry material. It can be seen that the amount of developed ice is almost two times lower in case of more concentrated diol solutions. In general, the amount of arisen ice is independent from cooling rate $\beta$ for all analysed solutions. The ice content equals about $0.636 \pm 0.003 \mathrm{~g} \mathrm{~g}^{-1}$ and $0.337 \pm 0.002 \mathrm{~g} \mathrm{~g}^{-1}$ for $5 \%$ and $10 \%$ ethylene glycol solution, respectively, and $0.484 \pm 0.007 \mathrm{~g} \mathrm{~g}^{-1}$, $0.228 \pm 0.002 \mathrm{~g} \mathrm{~g}^{-1}$ for $5 \%$ and $10 \%$ propylene glycol solution, respectively. In case of deionized water, the amount of developed ice is equal to $0.916 \pm 0.002 \mathrm{~g} \mathrm{~g}^{-1}$. Many studies have proved that during in-pore water freezing there always remains a non-freezable liquid layer on the pore wall, whose thickness is about $0.5-2.0 \mathrm{~nm}$ $[3,4]$. Significantly lower ice content in diol solutions in comparison with deionized water can be caused by considerable expansion of such a layer.

The first step leading to determination of the process rate function parameters is to estimate activation energy, which is obtained by means of differential Friedman method. This approach consists in drawing the relation between $\ln (\mathrm{d} \alpha / \mathrm{d} t)$ and reciprocal temperature for each 
(a)

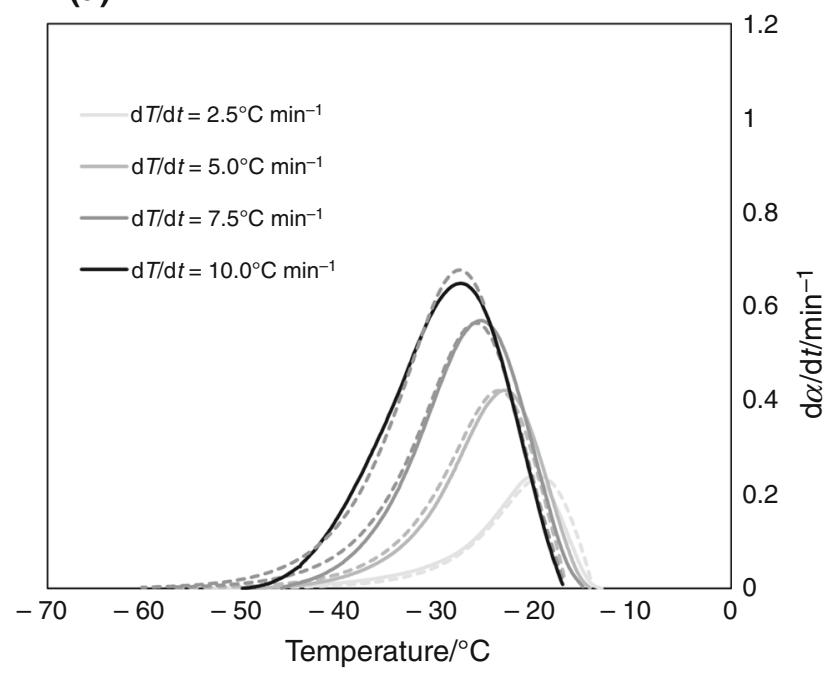

(c)

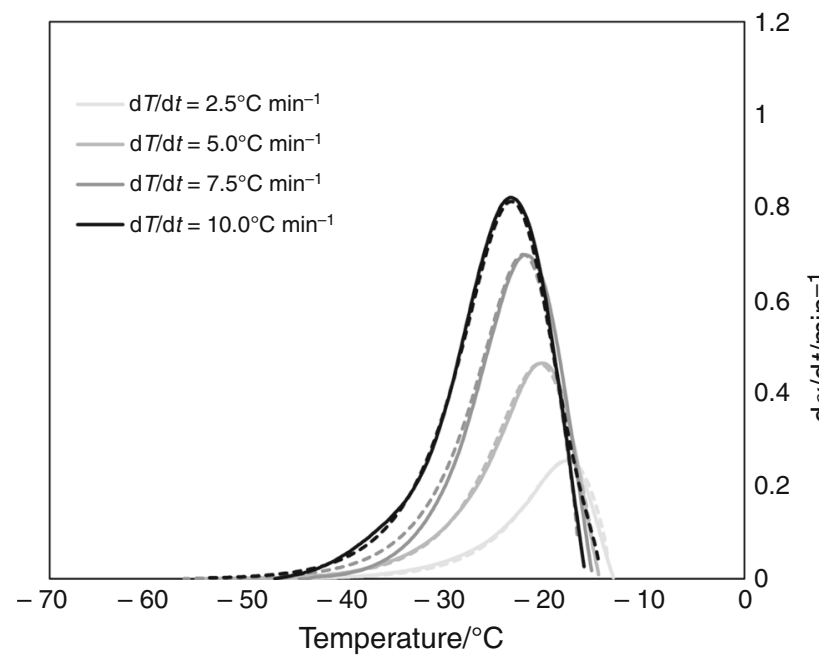

(b)

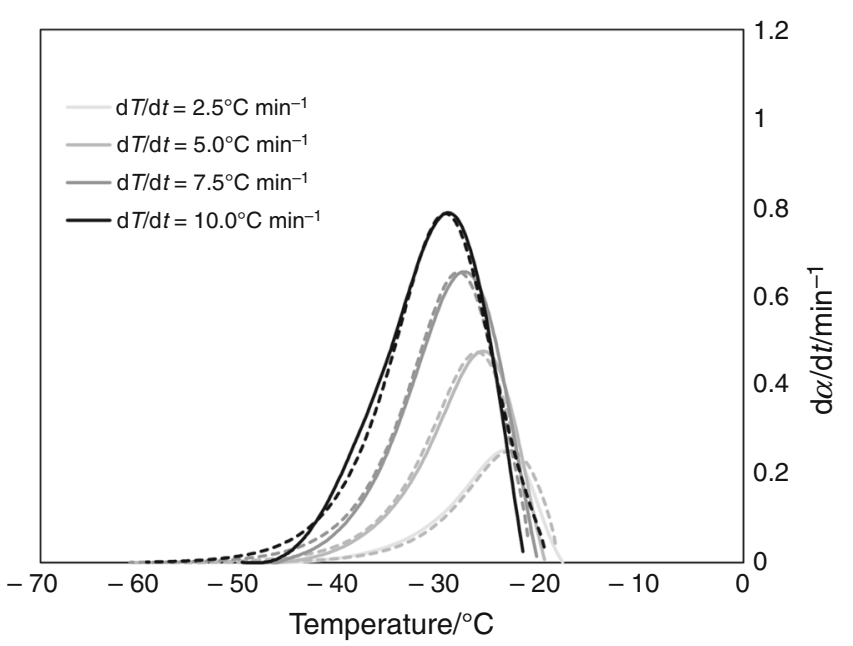

(d)

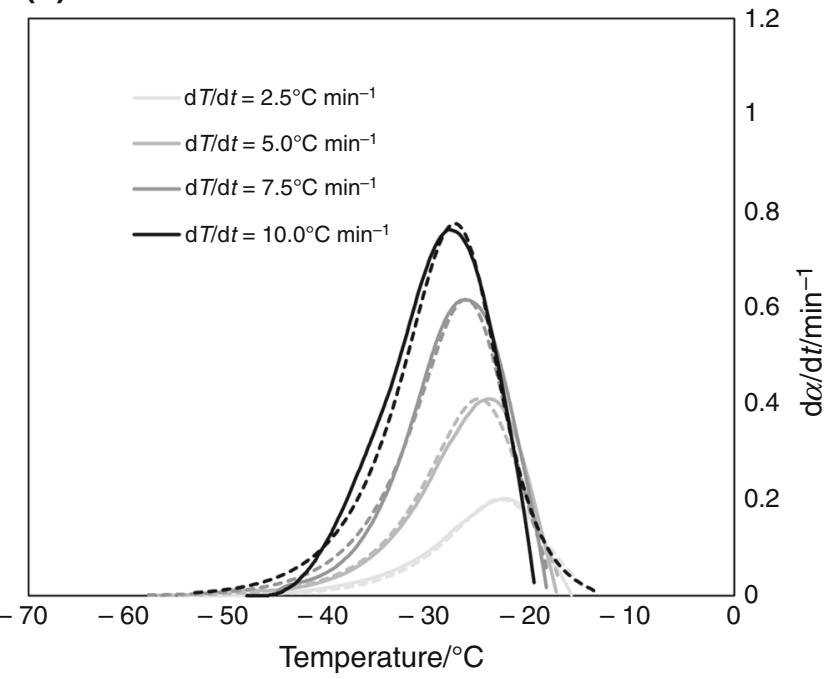

(e)

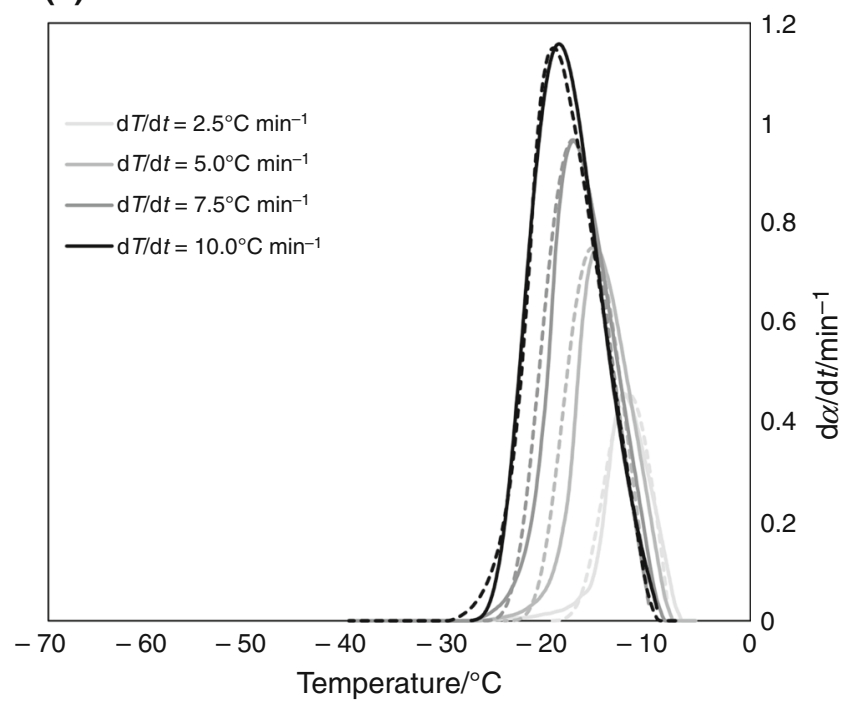


extent of conversion and each cooling rate. The activation energy is determined on the basis of this function slope. In conducted research, the activation energy is determined for $\alpha \in[0.2,0.8]$ with the step $\Delta \alpha=0.05$. Figure 6 presents the relation between activation energy $E_{\alpha}$ and temperature for each investigated material. It can be noticed that values of $E_{\alpha}$ are pretty similar in case of $5 \%$ ethylene glycol solution and deionized water, whereas for other investigated solutions the value of this parameter is significantly decreased, especially for $10 \%$ propylene glycol solution. In all analysed cases, the activation energy corresponds to negative value, which means that process pace increases along with the temperature decrease. In order to avoid dependence of all kinetic equation parameters on temperature, in further analysis the authors assumed the average values of activation energy for each studied substance, which are presented in Table 5.

Turnbull and Fisher [47] proposed an equation describing nucleation rate in condensed systems, which can be adapted to water solidification. It also enables to evaluate the activation free energy of nucleation $-\Delta G_{\mathrm{d}}$ according to the following formula:

$r=r_{0} \exp \left(\frac{-\Delta G_{\mathrm{d}}}{k_{\mathrm{B}} T}\right) \exp \left(\frac{-E_{\alpha}}{k_{\mathrm{B}} T}\right)$

where $r$ is the nucleation rate, $r_{0}$ is the pre-exponential factor, $k_{\mathrm{B}}$ is the Boltzmann constant and $-E_{\alpha}$ is the activation energy of diffusion.

The plots of relations between $\mathrm{d} \alpha / \mathrm{d} t$ function and extent of conversion $\alpha$ for each investigated liquid have their maximum at almost constant value of $\alpha$ independently of cooling rate, i.e. for $10 \%$ propylene glycol solution $\alpha=0.38 \pm 0.06$ - see Fig. 7. Hence, one may assume that the pressure in the liquid phase induced by solution solidification either does not affect the results or its influence is constant for each cooling rate.

In order to determine the most appropriate kinetic model and its parameters, the Málek's methodology is applied. His idea relies on the determination of the auxiliary functions $y(\alpha)$ and $z(\alpha)$ for the most popular kinetic models.
The $y(\alpha)$ function is proportional to kinetic model function $f(\alpha)$, which is why by drawing the $y(\alpha)$ dependence normalized in $(0,1)$ interval, the shape of $f(\alpha)$ is obtained [23]. One has to draw the auxiliary functions for analysed experimental data and select a proper kinetic equation by comparing their shapes to those ones reflecting kinetic models. The plots determined for the commonly applied kinetic equations as well as for obtained experimental data are presented in Fig. 8. The maximum values of $\mathrm{d} \alpha / \mathrm{d} t(\alpha)$, $y(\alpha)$ and $z(\alpha)$ functions are presented in Table 7 . It can be noticed that the plots of $y(\alpha)$ functions for every analysed solution are conceived in entire domain. Moreover, in all cases, the maximum of $y(\alpha)$ function $\left(\alpha_{M}\right)$ is contained in the range $\left(0, \alpha_{\mathrm{p}}\right)$, which indicates that Šesták-Berggren model is supposed to describe experimental data in the most accurate way.

In case of tests consisted of constant heating/cooling rate, the Šesták-Berggren model is based on the following formula [40]:

$f(\alpha)=\alpha^{\mathrm{m}}(1-\alpha)^{\mathrm{n}}$

where $m$ and $n$ are kinetic parameters, the so-called reaction orders, which are determined by applying the ratio $k$ :

$k=\frac{m}{n}$.

According to Málek's approach, the ratio $k$ is determined based on the maximum of auxiliary function $y(\alpha)$, which is denoted as $\alpha_{M}$ :

$k=\frac{\alpha_{\mathrm{M}}}{1-\alpha_{\mathrm{M}}}$

After simple mathematical transformations, Eq. (10) can be expressed as follows:

$\ln \left[\left(\frac{\mathrm{d} \alpha}{\mathrm{d} t}\right) \exp \left(\frac{E_{\alpha}}{R T_{\alpha}}\right)\right]=\ln A+n \ln \left[\alpha^{\mathrm{k}}(1-\alpha)\right]$.

One has to create a plot of relation between left-hand side of Eq. (20) and $n \ln \left[\alpha^{\mathrm{k}}(1-\alpha)\right]$, which is applied in order to determine the $n$ parameter as well as the preexponential factor $A$. The comparison between the
Table 6 Parameters of reduced SB model fitted to different reaction models

\begin{tabular}{lll}
\hline Model & $f(\alpha)$ & $\begin{array}{l}\text { Parameters of the equation } \\
c(1-\alpha)^{n} \alpha^{m}\end{array}$ \\
\hline JMA(2) & $2(1-\alpha)[-\ln (1-\alpha)]^{1 / 2}$ & $2.079(1-\alpha)^{0.806} \alpha^{0.515}$ \\
JMA(3) & $3(1-\alpha)[-\ln (1-\alpha)]^{2 / 3}$ & $3.192(1-\alpha)^{0.748} \alpha^{0.693}$ \\
F1 & $1-\alpha$ & $1-\alpha$ \\
R2 & $2(1-\alpha)^{1 / 2}$ & $2(1-\alpha)^{1 / 2}$ \\
R3 & $3(1-\alpha)^{2 / 3}$ & $3(1-\alpha)^{2 / 3}$ \\
D2 & $1 /[-\ln (1-\alpha)]$ & $0.973(1-\alpha)^{0.425} \alpha^{-1.008}$ \\
D3 & $1,5(1-\alpha)^{2 / 3} /\left[1-(1-\alpha)^{2 / 3}\right]$ & $4.431(1-\alpha)^{0.951} \alpha^{-1.004}$ \\
\hline
\end{tabular}


(a)

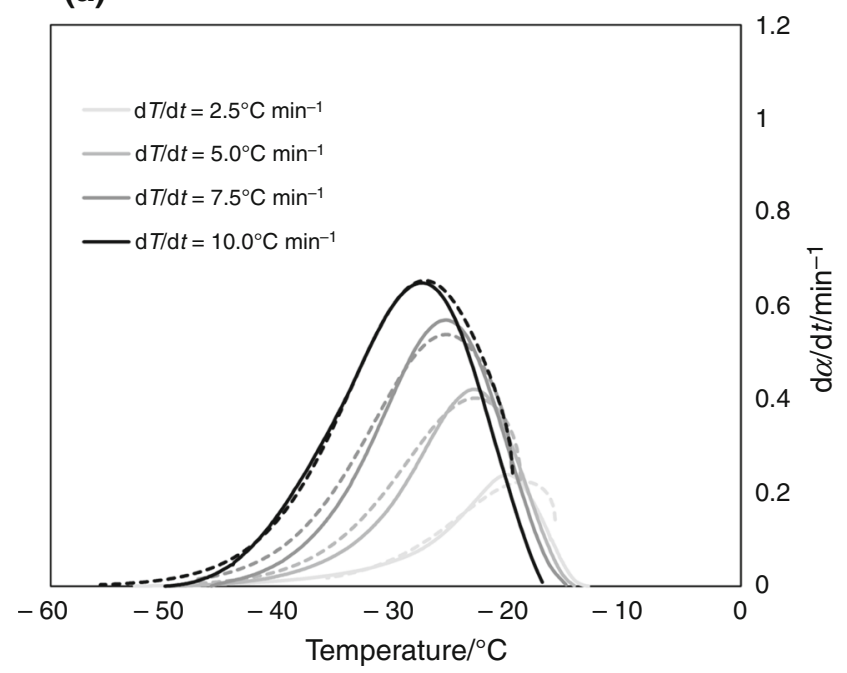

(c)

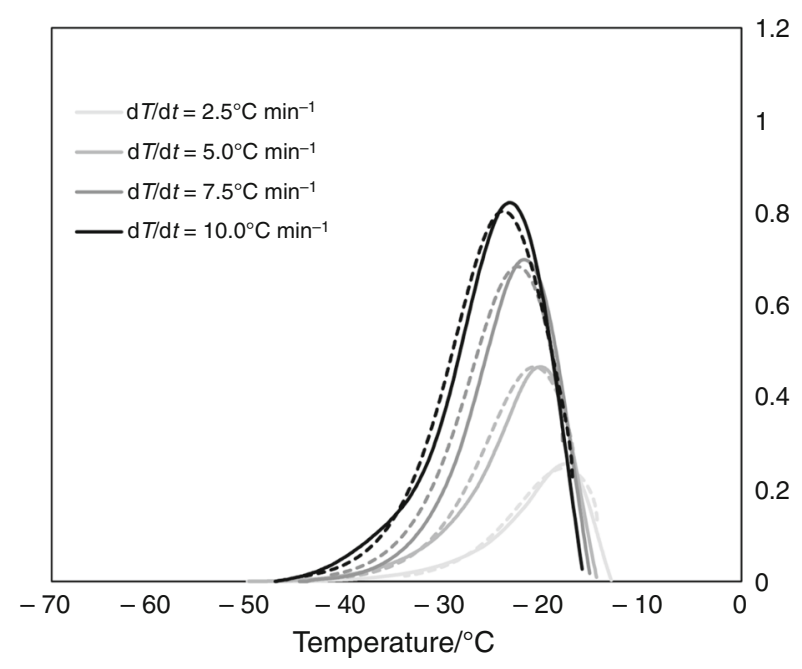

(b)

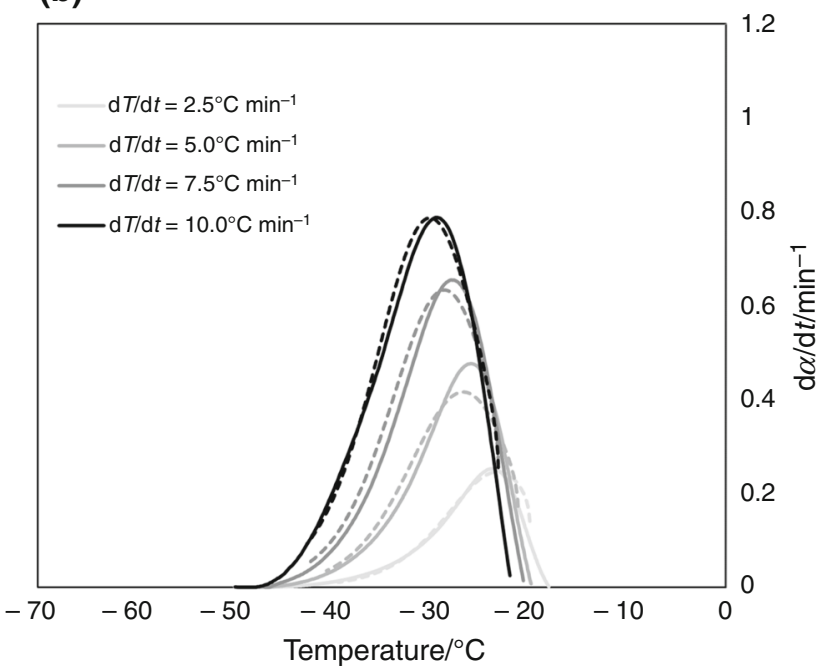

(d)

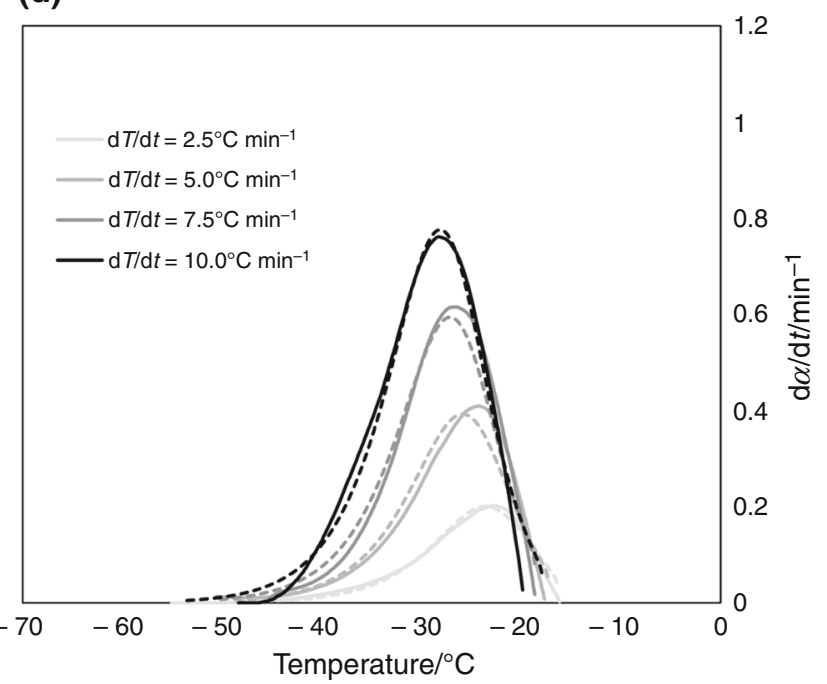

(e)

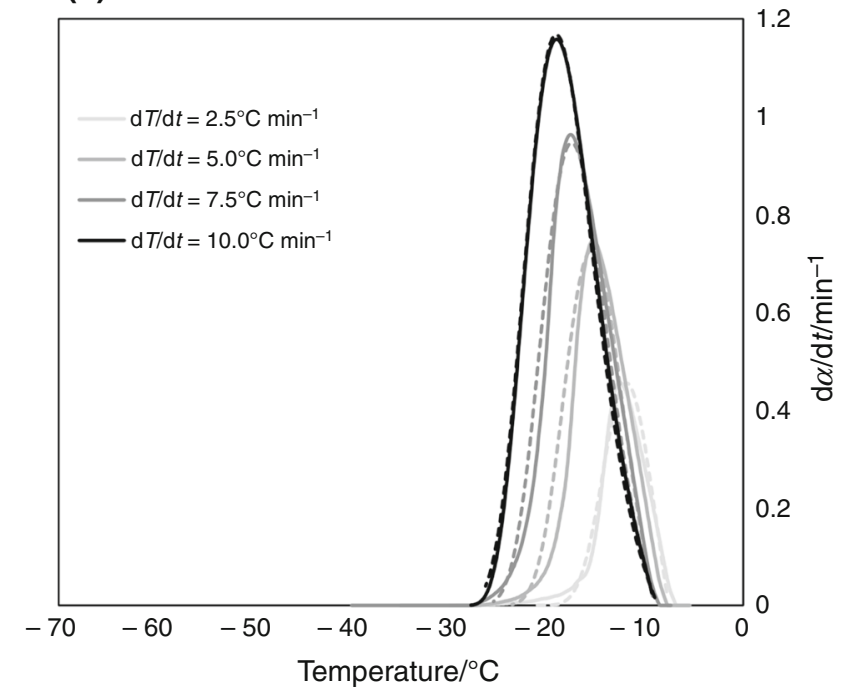

Fig. 10 Comparison of results obtained using Perez-Maqueda method for RO model with experimental data for 5\% ethylene glycol solution (a), $10 \%$ ethylene glycol solution (b), 5\% propylene glycol solution (c), 10\% propylene glycol solution (d) and water (e) 
experimental data and the results obtained by means of Šesták-Berggren model is presented in Fig. 9, whereas the kinetic parameters are presented in Table 7.

The second applied method leading to the determination of the most proper kinetic model is the one proposed by Perez-Maqueda and co-workers [26, 27]. The approach is based on the assumption that simplified form of ŠestákBerggren equation, after introducing constant $c$, corresponds to majority of kinetic models, Eq. (13). Parameters of reduced SB equation related to individual kinetic models are listed in Table 5. By connecting the simplified SB equation and Eq. (10), we obtain the following relation:

$\ln \left(\frac{\mathrm{d} \alpha / \mathrm{d} t}{(1-\alpha)^{n} \alpha^{m}}\right)_{\alpha, \beta}=\ln [c A]-\frac{E_{\alpha}}{R T}$.

It can be readily noticed that the right-hand side of Eq. (21) is a straight line. Furthermore, we maximize the Pearson correlation coefficient between the left-hand side of Eq. (21) and reciprocal temperature by optimizing $n$ and $m$ parameters of Eq. (13). A slope of this line corresponds to value of activation energy, whereas an intercept to preexponential factor and constant $c$.

In case of this so-called linear model-fitting method, the optimal values of kinetic parameters along with Pearson coefficients obtained for particular analysed substances are presented in Table 8 . Notice that these values of activation energy do not perfectly fit with the ones obtained using Friedman procedure. None of the determined optimal values reflects parameters of the physical models contained in Table 6, which is why the authors conduct the analysis on the existing physical model by estimating the Pearson coefficient. This indicates that the experimental data demonstrates the highest correspondence to the $n$th reaction order model, which is described by the following formula [23]:

$f(\alpha)=(1-\alpha)^{\mathrm{n}}$.

The comparison between the experimental data and the results obtained by means of $n$th reaction order model is presented in Fig. 10. The kinetic parameters of considered model are shown in Table 8.

Equation (22) is a general expression, which includes both R2 and R3 model for $n=0.5$ and $n=0.67$, respectively-see Table 6 . In case of those models, one assumes that nucleation occurs rapidly on the surface of the crystal. The rate of crystallization is controlled by the reaction interface progress from the centre of the crystal. Different cases of such a model can be derived depending on a shape of emerging crystal [48]. The R2 model corresponds to cylindrical volume whereas the R3 model to spherical/cubic volume. In case of analysed substances, we obtain up to four times larger values of $n$ parameter, which does not provide any physical meaning. However, the experimental data is reflected with precision and accuracy by reaction order model characterized by such parameter values.

\section{Conclusions}

The described research pertains to the crystallization kinetics of diols solutions, which are confined in mesopores whilst temperature decreases rapidly. Ethylene and propylene glycol in water solution, which are commonly applied as antifreeze, are used as in-pore liquid. As a saturated material, the mesoporous silica gel with dominant pore diameter of $11 \mathrm{~nm}$ is applied. The main purpose of this paper is to determine the influence of antifreeze addition on kinetic equation. To this end, the parameters of reaction rate function are estimated. The activation energy is determined by means of Friedman's method-see Fig. 6, as well as according to algorithm introduced by PerezMaqueda et al. [26, 27]-Table 8. In order to determine the kinetic mechanism, we applied the isoconversional method proposed by Málek [23] as well as the procedure for kinetic model determination the linear model-fitting method described by Perez-Maqueda et al. [26, 27]. In case of Málek's approach, the activation energy is estimated on the basis of Friedman method [25]. The experimental analysis is conducted by means of differential scanning calorimetry (DSC) with non-isothermal program with the following cooling rates employed: $2.5{ }^{\circ} \mathrm{C} \mathrm{min}{ }^{-1}, 5.0{ }^{\circ} \mathrm{C} \mathrm{min}{ }^{-1}$, $7.5^{\circ} \mathrm{C} \mathrm{min}{ }^{-1}$ and $10.0{ }^{\circ} \mathrm{C} \mathrm{min}^{-1}$. The conducted research enables authors to draw the following conclusions:

1. The ice content in diol solutions in comparison with deionized water is significantly lower. This fact may arise from the existence of much thicker non-freezable layer on pore walls in case of antifreeze solutions than in water. The thickness increases with rising diol solution concentration.

2. The value of activation energy obtained by means of Friedman method is negative and varies slightly as a function of temperature for all of analysed substances. This fact indicates that the process rate increases with the decreasing temperature. The activation energy decreases with the increasing concentration of glycols. Furthermore, ethylene and propylene glycol solutions solidifications are the complex processes, in which the apparent activation energy fluctuates, but activation energy values for individual processes are constant. To determine the rate functions, we assume the constant, average value of activation energy for all analysed solutions.

3. According to applied isoconversional method, it is settled that the empirical Šesták-Berggren formula 
reflects the experimental data with the high accuracy. Moreover, the second employed approach, the modelfitting method indicates that the $n$ th-order reaction model with fractal value of $n$ parameter also greatly resembles experimental results. To sum up the $n$ thorder reaction formula can be successfully applied to description of ethylene and propylene glycol solidification. The empirical SB formula might be applied for both water and glycol solutions.

4. The nitrogen adsorption-desorption isotherms as well as the pore size distributions obtained by means of nitrogen adsorption analysis for virgin samples as well as for samples subjected to ten freezing cycles are identical. This fact indicated that the silica gel microstructure does not undergo any deterioration caused by cyclic freezing of in-pore liquid.

Open Access This article is distributed under the terms of the Creative Commons Attribution 4.0 International License (http://creative commons.org/licenses/by/4.0/), which permits unrestricted use, distribution, and reproduction in any medium, provided you give appropriate credit to the original author(s) and the source, provide a link to the Creative Commons license, and indicate if changes were made.

\section{Appendix}

See Tables 7 and 8 .
Table 7 Kinetic parameters of SB model

\begin{tabular}{|c|c|c|c|c|c|c|c|}
\hline & $\alpha_{\mathrm{p}}$ & $\alpha_{\mathrm{M}}$ & $\alpha_{\mathrm{p}}^{\mathrm{inf}}$ & $p$ & $n$ & $m$ & $\ln A$ \\
\hline \multicolumn{8}{|c|}{$5 \%$ Ethylene glycol solution } \\
\hline 2.5 & 0.3232 & 0.2035 & 0.3153 & 0.2555 & 2.1831 & 0.5579 & -36.6260 \\
\hline 5 & 0.3832 & 0.2016 & 0.3621 & 0.2526 & 1.7648 & 0.4457 & -36.7030 \\
\hline 7.5 & 0.4068 & 0.1765 & 0.3879 & 0.2144 & 1.6070 & 0.3445 & -36.8680 \\
\hline 10 & 0.3755 & 0.1459 & 0.3647 & 0.1708 & 1.8729 & 0.3199 & -37.0210 \\
\hline Mean value & 0.3722 & 0.1819 & 0.3575 & 0.2233 & 1.8570 & 0.4170 & -36.8045 \\
\hline \multicolumn{8}{|c|}{$10 \%$ Ethylene glycol solution } \\
\hline 2.5 & 0.3336 & 0.1646 & 0.1609 & 0.1970 & 2.0931 & 0.4123 & -51.8720 \\
\hline 5 & 0.3583 & 0.1488 & 0.3424 & 0.1747 & 1.9457 & 0.3400 & -51.7930 \\
\hline 7.5 & 0.3765 & 0.1273 & 0.3765 & 0.1459 & 1.8437 & 0.2690 & -51.9270 \\
\hline 10 & 0.3694 & 0.1079 & 0.3563 & 0.1210 & 2.0600 & 0.2493 & -52.0590 \\
\hline Mean value & 0.3594 & 0.1371 & 0.3090 & 0.1597 & 1.9856 & 0.3176 & -51.9128 \\
\hline \multicolumn{8}{|c|}{ 5\% Propylene glycol solution } \\
\hline 2.5 & 0.2876 & 0.1241 & 0.2748 & 0.1417 & 2.4382 & 0.3454 & -62.7490 \\
\hline 5 & 0.3283 & 0.1188 & 0.3128 & 0.1348 & 2.3783 & 0.3206 & -62.7190 \\
\hline 7.5 & 0.3946 & 0.1095 & 0.3829 & 0.1230 & 2.0039 & 0.2464 & -62.8440 \\
\hline 10 & 0.3748 & 0.1039 & 0.3611 & 0.1159 & 2.3630 & 0.2739 & -62.8850 \\
\hline Mean value & 0.3463 & 0.1141 & 0.3329 & 0.1288 & 2.2959 & 0.2966 & -62.7993 \\
\hline \multicolumn{8}{|c|}{$10 \%$ Propylene glycol solution } \\
\hline 2.5 & 0.3235 & 0.0792 & 0.3235 & 0.0860 & 2.9140 & 0.2507 & -79.2830 \\
\hline 5 & 0.3389 & 0.0769 & 0.3389 & 0.0833 & 2.7623 & 0.2301 & -79.0650 \\
\hline 7.5 & 0.4241 & 0.0579 & 0.4036 & 0.0614 & 2.3654 & 0.1453 & -79.3540 \\
\hline 10 & 0.4249 & 0.0549 & 0.4122 & 0.0581 & 2.6931 & 0.1565 & -79.5190 \\
\hline Mean value & 0.3779 & 0.0672 & 0.3696 & 0.0722 & 2.6837 & 0.1957 & -79.3053 \\
\hline \multicolumn{8}{|c|}{ Deionized water } \\
\hline 2.5 & 0.5289 & 0.3804 & 0.5289 & 0.6141 & 1.0350 & 0.6356 & -37.6050 \\
\hline 5 & 0.5456 & 0.3436 & 0.5456 & 0.5234 & 0.8473 & 0.4435 & -37.7610 \\
\hline 7.5 & 0.5573 & 0.3015 & 0.5412 & 0.4316 & 0.8278 & 0.3573 & -37.9140 \\
\hline 10 & 0.5559 & 0.2441 & 0.5559 & 0.3230 & 0.7922 & 0.2559 & -38.1210 \\
\hline Mean value & 0.5469 & 0.3174 & 0.5429 & 0.4730 & 0.8756 & 0.4231 & -37.8503 \\
\hline
\end{tabular}


Table 8 Kinetic parameters of RO model

\begin{tabular}{llcll}
\hline & $n /-$ & $E_{a} / \mathrm{kJ} \mathrm{mol}^{-1}$ & $A /-$ & Person coefficient/- \\
\hline 5\% Ethylene glycol solution & 1.7630 & -88.973 & -42.989 & 0.9566 \\
10\% Ethylene glycol solution & 1.7630 & -109.543 & -53.396 & 0.9796 \\
5\% Propylene glycol solution & 1.9956 & -132.684 & -63.143 & 0.9809 \\
10\% Propylene glycol solution & 2.5636 & -166.624 & -80.515 & 0.9797 \\
Deionized water & 1.0207 & -102.880 & -47.684 & 0.9223 \\
\hline
\end{tabular}

\section{References}

1. Eames IW. Freezing and melting of water in spherical enclosures of the type used in thermal (ice) storage systems. Appl Therm Eng. 2002;22:733-45.

2. Chandrasekaran P, Cheralathan M, Kumaresan V, Velraj R. Enhanced heat transfer characteristics of water based copper oxide nanofluid PCM (phase change material) in a spherical capsule during solidification for energy efficient cool thermal storage system. Energy. 2014;22:636-42.

3. Defay R, Prigogine I, Bellemans A, Everett DH. Surface tension and adsorption. New York: Wiley; 1966.

4. Schreiber A, Ketelsen I, Findenegg GH. Melting and freezing of water in ordered mesoporous silica materials. Phys Chem Chem Phys. 2001;3:1185-95.

5. Ishikiriyama K, Todoki M, Motomura K. Pore size distribution (PSD) measurements of silica gels by means of differential scanning calorimetry: I. Optimization for determination of PSD. J Colloid Interface Sci. 1995;171:92-102.

6. Ishikiriyama K, Todoki M. Pore size distribution measurements of silica gels by means of differential scanning calorimetry: II. Thermoporosimetry. J Colloid Interface Sci. 1995;171:103-11.

7. Powers TC. A working hypothesis for further studies of frost resistance of concrete. J Am Concr Inst. 1945;41:245-72.

8. Coussy O, Monteiro PJM. Poroelastic model for concrete exposed to freezing temperatures. Cem Concr Res. 2008;38:40-8.

9. Koniorczyk M, Konca P. Experimental and numerical investigation of sodium sulphate crystallization in porous materials. Heat Mass Transf. 2013;49:437-49.

10. Gawin D, Koniorczyk M, Pesavento F. Modelling of hydrothermo-chemo-mechanical phenomena in building materials. Bull Pol Acad Sci Tech Sci. 2013;61:51-63.

11. Everett DH. The thermodynamics of frost damage to porous solids. T Faraday Soc. 1961;57:1541-51.

12. Powers TC, Helmuth RA. Theory of volume changes in hardened portland-cement paste during freezing. Highw Res Board Bull. 1953;32:285-97.

13. Zeng Q, Fen-Chong T, Dangla P, Li K. A study of freezing behavior of cementitious materials by poromechanical approach. Int J Solids Struct. 2011;48:3267-73.

14. Setzer MJ. Mechanical stability criterion, triple-phase condition, and pressure differences of matter condensed in a porous matrix. J Colloid Interface Sci. 2001;235:170-82.

15. Setzer MJ. Micro-ice-lens formation in porous solid. J Colloid Interface Sci. 2001;243:193-201.

16. Bronfenbrener L, Yarin L. Phase front propagation at freezing of fine dispersed soils. Eng Geol. 1989;56:805-10.

17. Bronfenbrener L, Korin E. Kinetic model for crystallization in porous media. Int J Heat Mass Transf. 1997;40:1053-9.

18. Murray BJ, Broadley SL, Wilson TW, Bull SJ, Wills RH, Christenson HK, Murray EJ. Kinetics of the homogeneous freezing of water. Phys Chem Chem Phys. 2010;12:10380-7.
19. Chégnimonhan V, Josset C, Peerhossaini H. Ice slurry crystallization based on kinetic phase-change modeling. Int J Refrig. 2010;33:1559-68.

20. Koniorczyk M, Bednarska D. Influence of the mesopore's diameter on the freezing kinetics of water. Microporous Mesoporous Mater. 2017;250:55-64.

21. Koniorczyk M, Konca P. Kinetics of water freezing in mesopores determined by differential scanning calorimetry. Int J Therm Sci. 2017;122:124-32.

22. Koniorczyk M, Bednarska D, Nowosielska M, Rynkowski J. Nucleation model for mesopore-confined water freezing kinetics. Int J Heat Mass Transf. 2018;120:575-86.

23. Málek J. The kinetic analysis of non-isothermal data. Thermochim Acta. 1992;200:257-69.

24. Vyazovkin S, Burnham AK, Criado JM, Pérez-Maqueda LA, Popescu C, Sbirrazzuoli N. ICTAC Kinetics Committee recommendations for performing kinetic computations on thermal analysis data. Thermochim Acta. 2011;520:1-19.

25. Friedman HL. Kinetics of thermal degradation of char-forming plastics from thermogravimetry. Application to a phenolic plastic. J Polym Sci C. 1964;6:183-95.

26. Pérez-Maqueda LA, Criado JM, Gotor FJ, Málek J. Advantages of combined kinetic analysis of experimental data obtained under any heating profile. J Phys Chem A. 2002;106:2862-8.

27. Pérez-Maqueda LA, Criado JM, Sánchez-Jiménez PE. Combined kinetic analysis of solid-state reactions: a powerful tool for the simultaneous determination of kinetic parameters and the kinetic model without previous assumptions on the reaction mechanism. J Phys Chem A. 2006;110:12456-62.

28. Srivastva U, Malhotra RK, Kaushik SC. Review of heat transport properties of solar heat transfer fluids. J Therm Anal Calorim. 2017;130:605-21.

29. Lörinczy D. Thermal analysis in biological and medical applications. J Therm Anal Calorim. 2017;130:1263-80.

30. Höhne GWH, Hemminger WF, Flammersheim H-J. Differential scanning calorimetry. New York: Springer; 2003.

31. Kambhatla PK, Ojjela O, Das SK. Viscoelastic model of ethylene glycol with temperature-dependent thermophysical properties: heat transfer enhancement with nanoparticles. J Therm Anal Calorim. 2019;135:1257-68.

32. Xian HW, Sidik NAC, Najafi G. Recent state of nanofluid in automobile cooling systems. J Therm Anal Calorim. 2019;135:981-1008.

33. Leena M, Srinivasan S. A comparative study on thermal conductivity of $\mathrm{TiO}_{2}$ /ethylene glycol-water and $\mathrm{TiO}_{2} /$ propylene glycol-water nanofluids. J Therm Anal Calorim. 2018;131:1987-98.

34. Randall M. International critical tables, V-VII. New York: McGraw-Hill; 1930.

35. Ishikiriyama K, Todoki M. Evaluation of water in silica pores using differential scanning calorimetry. Thermochim Acta. 1995;256:213-26. 
36. Sestak J. Thermal analysis, part D: Thermophysical properties of solids: their measurements and theoretical thermal analysis. New York: Elsevier; 1984.

37. Vyazovkin S. The handbook of thermal analysis and calorimetry, recent advances, techniques and applications, vol. 5. Amsterdam: Elsevier; 2008.

38. Database of Hazardous Materials created by National Oceanic and Atmospheric Administration U. S. Department of Commerce. https://cameochemicals.noaa.gov/. Accessed 21 July 2018.

39. Vyazovkin S, Sbirrazzuoli N. Isoconversional analysis of calorimetric data on nonisothermal crystallization of a polymer melt. J Phys Chem B. 2003;107:882-8.

40. Souza VC, SantoS EBC, Mendonça AV, Silva LB. Thermal behavior and decomposition kinetic studies of biomedical UHMWPE/vitamin C compounds. J Therm Anal Calorim. 2018;134:2097-105.

41. Gordina NE, Prokof'ev VY, Hmylova OE, Kul'pina YN. Effect of ultrasound on the thermal behavior of the mixtures for the LTA zeolite synthesis based on metakaolin. J Therm Anal Calorim. 2017;129:1415-27.

42. Vimalathithan PK, Barile CA, Vijayakumar CT. Investigation of kinetic triplets for thermal degradation of thermally cured vinyl ester resin systems and lifetime predictions. J Therm Anal Calorim. 2018;133:881-91.

43. Michaelsen C, Dahms M. On the determination of nucleation and growth kinetics by calorimetry. Thermochim Acta. 1996;288:9-27.

44. Fukusako S, Yamada M. Freezing characteristics of ethylene glycol solution. Heat Mass Transf. 1989;24:303-9.

45. Ayel V, Lottin O, Popa E, Peerhossaini H. Using undercooling to measure the freezing points of aqueous solutions. Int J Therm Sci. 2005;44:11-20.

46. ASTM Method D-1177-93a. Standard test method for freezing point of aqueous engine coolant. Philadelphia: American Society for Testing and Materials; 1989.

47. Turnbull D, Fisher JC. Rate of nucleation in condensed systems. J Chem Phys. 1949;17:71-3.

48. Khawam A. Application of solid-state kinetics to desolvation reactions. Ph.D. Thesis, University of Iowa. 2007.

Publisher's Note Springer Nature remains neutral with regard to jurisdictional claims in published maps and institutional affiliations. 